\title{
LGBQ+ adults' experiences of Improving Access to Psychological Therapies and primary care counselling services: informing clinical practice and service delivery
}

\author{
Amelia A.J. Foy, Daniel Morris, Vanessa Fernandes and Katharine A. Rimes*(i) \\ Institute of Psychiatry, Psychology and Neuroscience, King's College London, De Crespigny Park, London SE5 8AF, UK \\ ${ }^{\star}$ Corresponding author. Email: Katharine.Rimes@kcl.ac.uk
}

(Received 11 May 2019; revised 14 July 2019; accepted 23 July 2019)

\begin{abstract}
Lesbian, gay, bisexual, queer and other sexual minority (LGBQ+) people experience higher levels of psychological difficulties than heterosexual people. Evidence suggests that LGBQ+ treatment outcomes within England's Improving Access to Psychological Therapies (IAPT) services are worse than the outcomes for heterosexuals, especially for bisexual people and sexual minority women. IAPT services provide evidence-based treatments like cognitive behavioural therapy (CBT), typically for anxiety or depression. This study explored LGBQ+ adults' experiences with IAPT services and/or primary care counselling. LGBQ+ adults $(n=136)$ answered an online questionnaire (fixed-response and optional open-ended questions) about their access and treatment experiences. Descriptive statistics summarized multiple-choice responses. Qualitative data were analysed through thematic analysis. Before access, $41.9 \%$ of participants were concerned about experiencing LGBQ+ stigma/discrimination within psychological services. Only $13.2 \%$ of participants thought their sexuality negatively impacted their treatment, although prejudice/ discrimination may be underestimated as $33.6 \%$ participants did not disclose their sexuality to practitioners and sexuality was not discussed in treatment for $44.0 \%$ of participants. Bisexual clients were significantly less likely to disclose their sexuality. The barriers LGBQ+ people described within IAPT or primary care services included: feared or experienced stigma in the services; reluctance to disclose sexuality; inconsistent discussion of sexuality in treatment; a lack of awareness and understanding towards LGBQ+ identities and community-specific challenges; and distrust, disillusionment and exclusion resultantly. Overall, $52.2 \%$ thought services could be improved for LGBQ+ individuals. This study identified multiple issues to be addressed in therapist training and service development.
\end{abstract}

\section{Key learning aims}

(1) The unique needs/experiences that LGBQ+ people bring to therapy, such as the need to disclose their sexuality and past experiences of stigma/discrimination, including how this differs within the community (e.g. bisexual people or LGBQ+ Black and minority ethnic people).

(2) How these needs/experiences can result in barriers that make their treatment experience distinct from heterosexuals and influence their treatment outcomes.

(3) What steps should be taken in future research and clinical practice to ensure improvements in the psychological treatment experiences of $\mathrm{LGBQ}+$ people, including in relation to therapist understanding and training in LGBQ+-related issues.

Keywords: anxiety; counselling; depression; sexual orientation; treatment; therapy 


\section{Introduction}

\section{$L G B Q+$ mental health}

Research has indicated that sexual minorities (such as those identifying as lesbian, gay, bisexual or queer; LGBQ+) experience higher rates of psychological difficulties such as anxiety, depression or suicidality than heterosexual people (Plöderl and Tremblay, 2015; Semlyen et al., 2016). Bisexual individuals tend to experience higher rates of psychological disorders compared with the lesbian and gay community (Plöderl and Tremblay, 2015; Semlyen et al., 2016).

It has been proposed that a significant contributor to the mental health disparities are chronic, socially based stressors that are unique to sexual minorities. Minority stress theory suggests that stigmatizing and discriminatory social environments give rise to stressors that cause the excess rates of mental health problems (Meyer, 2003). This theory proposes that stressors exist on a distal (external) to proximal (internal) continuum: distal stressors may include direct prejudice/discrimination, whilst proximal stressors involve the internalizing of anti-LGBQ+ stigma. Minority stressors may be different for bisexual people, as biphobia differs from homophobia, and may include: double discrimination (i.e. from both heterosexual people and lesbian or gay individuals); invalidation and erasure of bisexuality; and higher levels of sexual victimization (Doan Van et al., 2019). There is evidence that minority stressors may be a significant contributor to mental health disparities between sexual minority individuals and heterosexual individuals (Hatzenbuehler and Pachankis, 2016), and for minority stress uniquely impacting bisexual people, e.g. through exclusion and stereotyping from within the LGBQ+ community (Balsam and Mohr, 2007; Bostwick and Hequembourg, 2014; Dyar and London, 2018; Feinstein et al., 2016). As this evidence is largely cross-sectional, causation cannot be determined, i.e. whether minority stress leads to depression/anxiety, or depression/ anxiety increases the perception, memory or reporting of minority stressors. Further research is needed from longitudinal and intervention studies.

Victimization is one minority stressor likely to contribute to sexual orientation mental health disparities. LGBQ+ individuals are more likely than heterosexual individuals to experience victimization, both in childhood and adulthood (Andersen and Blosnich, 2013; Friedman et al., 2011; Mittleman, 2019; $\mathrm{Xu}$ and Zheng, 2015). Research further shows that victimization is associated with poorer LGBQ+ mental health (Mustanski et al., 2016 Russell et al., 2011). One possible mechanism is via gender non-conformity (differing from your assigned gender role through behaviours, clothing, interests or otherwise) as a visible marker of difference. Childhood gender non-conformity is more common in people who subsequently report same-sex attractions (Li et al., 2017; Steensma et al., 2012). Childhood gender non-conformity is associated with increased risk for bullying and child abuse (Roberts et al., 2012; Roberts et al., 2013).

Sexual minority individuals may also be concerned about experiencing stigma or rejection, and experience hypervigilance to potential threat and worries about sexual orientation disclosure as a result. As LGBQ+ identities are usually concealable, there is increased ambiguity in social situations depending on the salience of LGBQ+ stigma, the threat of discovery, and its perceived consequences (Pachankis, 2007). One study found that non-disclosure was highly associated with worse psychological wellbeing at a 1-year follow-up (Durso and Meyer, 2013), whilst the reverse effect can occur when one discloses in a supportive context (Legate et al., 2012).

Thus LGBQ+ people encounter stressors and challenges that their heterosexual peers do not, which may contribute to their elevated rates of mental illness.

\section{$L G B Q+$ treatment access and outcome}

In line with their elevated rates of psychological disorders, there is some evidence that LGBQ+ people access mental health services more than their heterosexual counterparts, e.g. higher mental health-related general practitioner appointments or counselling (Chakraborty et al., 2011). Under 
the 2010 Equality Act, sexual orientation is a protected characteristic. As such, LGBQ+ people should not experience discrimination within the UK National Health Service (NHS), or experience indirect and unintentional barriers to accessing services, such as through the use of heteronormative language or images. Several recommendations have been proposed to ensure the equal treatment of LGBQ+ people in health services, including routine monitoring of sexuality (in clients and practitioners) and mandatory LGBQ+ equality training (NHS, 2015). Furthermore, in recent years, steps have been taken to stop conversion therapy - the practice of attempting to change an individual's sexuality using psychological interventions. The Memorandum of Understanding on Conversion Therapy in the UK (2017; see: https://www. bpc.org.uk/sites/psychoanalytic-council.org/files/MoU2_FINAL_0.pdf) has been signed by the British Association of Behavioural and Cognitive Psychotherapies (BABCP) and other major UK therapeutic bodies, stating that attempts to change clients' sexual orientations are unethical, ineffective and potentially harmful.

Despite efforts to minimize sexual orientation discrimination within the NHS, sexual minorities are more likely to report unfavourable experiences with NHS primary care than heterosexuals (Elliott et al., 2015). There is also evidence of disparities in treatment outcomes for sexual minority adults in Improving Access to Psychological Therapies (IAPT) services in England. IAPT services provide psychological interventions in the UK under the NHS and aim to reach populations that have not accessed mental health help as frequently as others (NHS, 2017). Rimes and colleagues (Rimes et al., 2018; Rimes et al., 2019) found that finalsession scores for depression, anxiety and functional impairment were worse in lesbian or bisexual women than heterosexual women. Lesbian and bisexual women were also less likely to reliably recover than heterosexual women. Bisexual men, compared with gay and heterosexual men, also had higher depression, anxiety and functional impairment on finalsession scores, and were also less likely to reliably recover (Rimes et al., 2019). No significant differences were found in treatment outcomes between gay and heterosexual men.

Given the disparities in satisfaction and reliable recovery that exist between LGBQ+ and heterosexual populations, it is arguable that IAPT and primary care services are not consistently meeting the treatment needs of LGBQ+ adults with psychological problems, especially for bisexual clients and sexual minority women. This is particularly concerning given that sexual minorities constitute a stigmatized group who are at high risk for developing mental health disorders due to their experiences with prejudice and discrimination. This also complicates the link between service delivery and treatment outcome, due to confounding variables such as increased childhood victimization, or stigma throughout society.

\section{Aims}

Research is needed to identify any possible factors in IAPT or primary care psychological intervention services which may contribute to poor treatment experiences or outcomes for LGBQ+ people, especially for bisexual people and sexual minority women. This is an exploratory study into the experiences of LGBQ+ adults who attempted to access IAPT services or primary care counselling for difficulties such as anxiety and depression. This aims to identify LGBQ+ adults' experiences of accessing and receiving psychological interventions from IAPT services or primary care counselling and their views on how to improve services for sexual minorities.

\section{Method}

Design

This study consisted of an online questionnaire of both forced-choice questions and open-answer questions to collect quantitative and qualitative data. 


\section{Procedure}

This study was approved by King's College London Research Ethics Committee (HR-17/18-5303). Participants were recruited through purposive sampling from LGBTQ+ and mental health websites, social media and around King's College London. Recruitment advertisements indicated that the study was for LGBQ+ adults who had experiences of being referred or receiving NHS care for mild to moderate psychological difficulties (e.g. depression, anxiety, stress or other problems). Transgender people, who are included in the typical acronym (LGBT or LGBTQ+), were not specifically recruited for this study, but could partake if they were also a sexual minority. The experiences and service needs of sexual minority and gender minority people may overlap but are also often different; separate research is needed focusing on trans and non-binary individuals. LGBTQ+ will be used in this paper where themes arise from our participants that involved the experiences of trans people. Advertisements told participants that research aimed to improve NHS IAPT and primary care psychological services for LGBQ+ individuals, informed them of their right to withdraw, confidentiality, possible distress questions may cause, alongside who to contact for further questions and the dissemination of results. Interested participants were directed to an online information sheet and a consent form which participants had to complete before proceeding to the survey. The survey closed with information about sources of support if needed.

\section{Participants}

A total of 136 participants completed this study with an average age of 29.6 years. Most participants were White British $(n=108 ; 79.4 \%)$ with two $(1.5 \%)$ White Irish people, two (1.5\%) White Travellers, five (3.6\%) mixed raced people, one $(0.7 \%)$ Indian and one $(0.7 \%)$ Arab person. The highest educational qualifications were school/college exams at the age of 18 for 43 participants (31.6\%) and a university degree for 53 participants (39.0\%).

Assigned sex at birth indicated $90(66.2 \%)$ female and $46(33.8 \%)$ male participants. For gender identity, there were $70(51.5 \%)$ cisgender women, one (0.7\%) trans woman, $38(27.0 \%)$ cisgender men, three $(2.2 \%)$ trans men, and $14(10.3 \%)$ non-binary individuals (non-binary included gender-fluid, cross-dresser, agender, questioning and 'other' options). Cisgender refers to an individual whose assigned sex at birth matches their gender identity.

Sexuality was measured through tick-box options and a final option of 'other: please specify'. There were 32 (23.5\%) gay, 25 (18.4\%) lesbian, 51 (37.5\%) bisexual, 17 (12.5\%) queer, eight (5.9\%) 'other' (identifying as pansexual, attraction regardless of gender), two (1.5\%) asexual participants, and one $(0.7 \%)$ mostly heterosexual participant. Of the three largest sexual identities reported, the bisexual group consisted of seven (13.7\%) cisgender men and one (2.0\%) trans man, $31(60.8 \%)$ cisgender women and one (2.0\%) trans woman, and $11(21.6 \%)$ non-binary people. The gay sample was $29(90.6 \%)$ cisgender men, two (6.3\%) trans men and one (3.1\%) non-binary person. The lesbian sample was $24(96 \%)$ cisgender women and one (4\%) trans woman.

\section{Measures}

Questions were created for this study due to lack of suitable existing measures (questions available on request from the corresponding author). First, there were questions about why participants sought psychological support, and whether they felt their experiences of sexuality-based stigma and/or discrimination related to their psychological difficulties. Secondly, the questionnaire investigated whether their LGBQ+ identity had any impact on their referral, assessment and psychological treatment. Thirdly, they were asked if and when they disclosed their sexual orientation at different stages along the treatment pathway. Fourthly, they were asked if and how treatments could be improved for LGBQ+ individuals. Finally, participants were asked for their views about different types of possible specific LGBQ+ forms of intervention. 
Throughout the questionnaire, the option for further comment was offered in order to gather written responses.

\section{Data analysis}

Responses to fixed response questions were analysed using SPSS. Descriptive statistics were used to summarize responses for the whole sample for the fixed-choice questions. Inferential statistical tests (chi squared for discrete data and independent $t$-tests for continuous data) were used to compare responses between monosexual (lesbian and gay, $n=53$ ) and multi-gender attracted (bisexual+, i.e. bisexual and pansexual, $n=58)$ participants, as well as between cisgender men $(n=38)$ and cisgender women $(n=70)$. Due to the exploratory nature of this study, it was judged preferable to identify possible differences that could be tested in future research than to miss potentially important differences. Consequently, no adjustments were made for multiple comparisons.

Thematic analyses were used for responses to open-answer questions (completed by 130 of the participants) relating to treatment experiences and how to improve them, in line with guidance from Braun and Clarke (2006). This analysis was epistemologically realist, taking participants' answers as directly reflective of their realities, and inductive, as this study is exploratory rather than theoretically driven. However, thematic analysis, as an active process, will always be influenced by the investigator's worldview (Braun and Clarke, 2006). Analysis to identify latent themes was conducted in six phases, including familiarizing oneself with the data, assigning codes to written responses, and examining for patterns across these codes. Themes were initially identified by the first author and discussed with the other authors.

\section{Results}

\section{Mental health and stigma}

The primary problem descriptors participants presented with were depression $(n=110,80.9 \%)$ and anxiety $(n=98,72.1 \%)$, followed by low mood $(n=69,50.7 \%)$ and suicidal thoughts $(n=72$, $52.9 \%)$; some participants presented with more than one of these difficulties. Other problems included stress $(n=57,41.9 \%)$, social anxiety $(n=51,37.5 \%)$, self-harm $(n=41,30.1 \%)$, low self-esteem $(n=40,29.4 \%)$ and suicidal behaviours $(n=27,19.9 \%)$.

The extent that participants' perceived sexuality-based stigma and discrimination had impacted their psychological difficulties was as follows: $27.9 \%$ participants said 'not at all', $31.6 \%$ said 'a little', $17.6 \%$ said 'a moderate amount' and $17.6 \%$ said 'a large amount'. Seven participants stated they did not know (5.1\%).

\section{Referral, assessment and treatment received}

See Appendix 1 for all results regarding referral routes and assessment. The majority of participants were referred through their GP (62.5\%), followed by self-referral $(22.8 \%)$. Postreferral, $96.3 \%$ were offered an assessment, $74.3 \%$ were offered treatment and $66.9 \%$ actually started treatment. Of those offered treatment, $68.6 \%(n=70)$ of participants completed it. Of those who started treatment, most received CBT (69.9\%). The mean number of treatment sessions received was $11.6(S D=7.9)$. Of those who received treatment, $85.7 \%$ received a oneto-one intervention, whilst $11 \%$ received a group intervention.

\section{$L G B Q+$ experiences of psychological care}

Participants' responses to questions asking about their treatment experience can be seen in Table 1 for the overall sample, and Table 2 for those who received treatment. Key findings are summarized below. 
Table 1. LGBQ+ clients' experiences of referral/access $(n=136)$

\begin{tabular}{|c|c|c|c|c|c|c|}
\hline \multirow{2}{*}{$\begin{array}{l}\text { Experiences and perceptions of stigma/discrimination during treatment referral } \\
\text { and access }(n=136)\end{array}$} & \multicolumn{2}{|c|}{ Yes } & \multicolumn{2}{|c|}{ No } & \multicolumn{2}{|c|}{$\begin{array}{l}\text { Not } \\
\text { sure }\end{array}$} \\
\hline & $n$ & $\%$ & $n$ & $\%$ & $n$ & $\%$ \\
\hline $\begin{array}{l}\text { Before you were referred to an NHS counsellor or psychological treatment } \\
\text { service, had you been at all concerned that you might experience any } \\
\text { discrimination or stigma that may have been related to your sexual } \\
\text { orientation or any other characteristic or experience? }\end{array}$ & 57 & 41.9 & 60 & 44.1 & 19 & 14.0 \\
\hline $\begin{array}{l}\text { During any part of the journey from trying to access help for your psychological } \\
\text { problems (e.g. from your GP) through to the point where you were discharged } \\
\text { from the NHS counsellor or psychological treatment service, did you } \\
\text { experience any discrimination or prejudice related to your sexual orientation } \\
\text { (or which may have related to this)? }\end{array}$ & 21 & 15.4 & 99 & 72.8 & 16 & 11.8 \\
\hline $\begin{array}{l}\text { Have you ever found that your sexual orientation caused any difficulties for you } \\
\text { in relation to accessing support for psychological difficulties in the NHS? }\end{array}$ & 11 & 16.2 & 103 & 75.7 & 11 & 8.1 \\
\hline $\begin{array}{l}\text { Do you feel that the treatment you received by this service was affected in a } \\
\text { negative way because of your sexual orientation? }\end{array}$ & 18 & 13.2 & 100 & 73.5 & 18 & 13.4 \\
\hline $\begin{array}{l}\text { Do you think that therapists should undergo specific training for working with } \\
\text { LGBQ+ people? }\end{array}$ & 119 & 87.5 & 7 & 5.1 & 10 & 7.4 \\
\hline $\begin{array}{l}\text { Do you think the care provided by the talking therapies service could have been } \\
\text { improved for LGBQ+ people? }\end{array}$ & 71 & 52.2 & 14 & 10.3 & 51 & 37.5 \\
\hline $\begin{array}{l}\text { Were you asked about your sexual orientation by the counsellor or service to } \\
\text { which you were referred? }\end{array}$ & 39 & 28.7 & 80 & 58.8 & 17 & 12.5 \\
\hline Did you disclose your true sexual orientation?* & 76 & 56.7 & 45 & 33.6 & 13 & 9.7 \\
\hline Could questions about sexual orientation have been improved?* & 47 & 35.1 & 31 & 23.1 & 56 & 41.8 \\
\hline
\end{tabular}

${ }^{\star}$ Two participants did not answer; $n=134$.

Table 2. LGBQ+ clients' experiences of treatment

\begin{tabular}{|c|c|c|c|c|c|c|c|c|}
\hline \multirow{2}{*}{$\begin{array}{l}\text { Did treatment address their experiences as a sexual minority person? } \\
\text { (for those who received treatment; } n=91 \text { ) }\end{array}$} & \multicolumn{2}{|c|}{ Yes } & \multicolumn{2}{|c|}{ No } & \multicolumn{2}{|c|}{$\begin{array}{l}\text { Not } \\
\text { sure }\end{array}$} & \multicolumn{2}{|c|}{ N/A } \\
\hline & $n$ & $\%$ & $n$ & $\%$ & $n$ & $\%$ & $n$ & $\%$ \\
\hline $\begin{array}{l}\text { Did you receive counselling or other treatment specifically designed for } \\
\text { LGBQ+ people? }\end{array}$ & 0 & 0.0 & 89 & 97.8 & 2 & 2.2 & - & - \\
\hline  & 14 & 15.7 & 75 & 84.3 & 0 & 0.0 & - & - \\
\hline During your treatment, was your sexual orientation discussed? & 44 & 48.4 & 40 & 44.0 & 7 & 7.7 & - & - \\
\hline $\begin{array}{l}\text { Did your therapist ask if your experiences as an LGBQ+ person (e.g. } \\
\text { stigma and discrimination) might relate to your presenting problems } \\
\text { or treatment? }\end{array}$ & 16 & 19.8 & 47 & 58.0 & 8 & 9.9 & 10 & 12.3 \\
\hline \multicolumn{9}{|c|}{ Therapist knowledge and understanding (for those who received one-to-one or group treatment; $n=81$ ) } \\
\hline $\begin{array}{l}\text { Were there any issues that you did not feel able to discuss with your } \\
\text { therapist because of your sexual orientation? }\end{array}$ & 22 & 27.2 & 41 & 50.6 & 12 & 14.8 & 6 & 7.4 \\
\hline $\begin{array}{l}\text { Did you feel that your therapist had a good enough understanding of } \\
\text { issues relating to your experiences as an LGBQ+ person? }\end{array}$ & 18 & 22.2 & 33 & 40.7 & 14 & 17.3 & 16 & 19.8 \\
\hline $\begin{array}{l}\text { Do you think that being LGBQ+ impacted on the relationship with your } \\
\text { therapist in any way? }\end{array}$ & 28 & 35.4 & 47 & 59.5 & 0 & 0.0 & 4 & 5.1 \\
\hline $\begin{array}{l}\text { If you do not think being LGBQ+ impacted on the relationship, do you } \\
\text { think it would have improved treatment if they had had better } \\
\text { understanding? }{ }^{\star \star}\end{array}$ & 28 & 35.4 & 10 & 12.7 & 15 & 19.0 & 26 & 32.9 \\
\hline $\begin{array}{l}\text { If you received a group intervention, did you reveal your sexual } \\
\text { orientation to others in the group? }(n=10)\end{array}$ & 1 & 1.2 & 17 & 21.0 & 2 & 2.5 & 61 & 75.3 \\
\hline \multicolumn{9}{|l|}{ Participant preferences for therapist sexual orientation and gender $(n=81)$} \\
\hline $\begin{array}{l}\text { Before you started treatment, would you have preferred to see a } \\
\text { therapist with a particular sexual orientation? }\end{array}$ & 22 & 27.2 & 46 & 56.8 & 12 & 14.8 & 1 & 1.2 \\
\hline $\begin{array}{l}\text { Before you started treatment, would you have had a preferred to see a } \\
\text { therapist of a particular gender? }\end{array}$ & 44 & 54.3 & 30 & 37.0 & 6 & 7.4 & 1 & 1.2 \\
\hline $\begin{array}{l}\text { In retrospect, would you have preferred a therapist with a certain sexual } \\
\text { orientation? }\end{array}$ & 30 & 37.0 & 30 & 37.0 & 20 & 24.7 & 1 & 1.2 \\
\hline In retrospect, would you have preferred a therapist with a certain gender? & 39 & 48.1 & 32 & 39.5 & 5 & 6.2 & 5 & 6.2 \\
\hline $\begin{array}{l}\text { Before you started treatment, would you have preferred to see a } \\
\text { therapist with a particular sexual orientation? }\end{array}$ & 22 & 27.2 & 46 & 56.8 & 12 & 14.8 & 1 & 1.2 \\
\hline
\end{tabular}




\section{Experiences and perceptions of stigma/discrimination during treatment referral and access}

Of the participant sample, $41.9 \%$ were concerned prior to referral that they may experience stigma/discrimination in the process of accessing psychological help. Regarding actually encountering stigma/discrimination, $15.4 \%$ reported experiencing this during this process, and $16.2 \%$ found their sexuality caused difficulties in accessing psychological support. A further $13.2 \%$ felt their sexuality negatively impacted their treatment. A large majority $(87.5 \%)$ said therapists should undergo specific training to work with LGBQ+ people, with $35.1 \%$ reporting that care could be improved for LGBQ+ people.

\section{Sexual orientation monitoring and disclosure}

Of the overall sample, $58.8 \%$ of participants reported not being asked about their sexual orientation by the counsellor or service they were referred to; a further $33.6 \%$ did not disclose their true sexual orientation. Of those who received treatment, just under half $(48.4 \%)$ of participants reported discussing their sexual orientation during treatment.

\section{Did treatment address their experiences as a sexual minority person?}

No participants reported receiving treatment designed specifically for LGBQ+ people and $84.3 \%$ of participants reported that their treatment did not reference their sexual orientation. A further $58 \%$ of participants reported that their therapist did not ask whether their experiences as an LGBQ+ person related to their presenting problems or treatment.

\section{Therapist knowledge and understanding}

Of the 70 participants who received one-to-one or group therapy, 27.2\% felt there were issues they could not discuss with their therapist, and $35.4 \%$ felt being LGBQ+ impacted the therapeutic relationship. Furthermore, $40.7 \%$ of participants felt that their therapist did not have a good enough understanding of issues relating to the experience of being LGBQ+, and $35.4 \%$ thought that an increased understanding of LGBQ+ issues and experiences would have improved the relationship.

\section{Participant preferences for therapist sexual orientation and gender}

Of those who received treatment, $27.2 \%$ said that before treatment they would have preferred a therapist of a certain sexual orientation, but $37 \%$ said in retrospect that they would have preferred a therapist of a certain sexual orientation. The proportions who would have preferred a therapist of a certain gender differed (54.3\%, and after treatment $48.1 \%)$.

\section{Treatment delivery preferences}

Participant responses regarding their treatment delivery preferences are shown in Table 3. Oneto-one therapy was most popular, with $83.1 \%$ of participants saying this should be offered, but participants overall felt that all formats should be offered: face-to-face groups $(72.1 \%)$, bisexualonly groups $(52.9 \%)$, online groups $(57.4 \%)$, online videos $(72.1 \%)$, apps $(50.7 \%)$, family-based support (74.1\%) and partner-based support (69.9\%). Regarding their own preferences, one-toone therapy and online videos were the most popular interventions (61.0 and 61.8\%, respectively), and family therapy was the least popular (24.3\%).

Whether participants felt that interventions should be delivered separately for men and women varied, with a largely even split across the sample for each treatment type. Face-to-face groups were most requested to be delivered separately (35.3\% of participants saying 'yes'), whilst apps 
being designed for men and women separately was least requested (20.6\% of participants saying 'yes').

Regarding individual topics, the most interest was expressed in accessing support around how being LGBQ+ affects your mental health (81.6\% of participants). In fact, participants expressed great interest in accessing help via the NHS for all the topics listed (see Table 4) except for coming out about your sexual orientation. A further $80.9 \%$ of participants reported that there should be an NHS service specifically for lesbian and bisexual women to cope with the effects of childhood abuse, with $5.9 \%$ saying there should not, and $13.2 \%$ unsure.

\section{Differences between monosexual and multi-gender attracted participants}

There were no significant differences in the responses between people with same-sex and multiple-sex attractions for most variables. The exceptions were as follows: bisexual+ people were significantly less likely to have disclosed their sexual orientation to practitioners than their lesbian and gay counterparts $\left[\chi^{2}(2,114)=18.8, p<0.001\right]$. Bisexual+ participants were also more likely to have felt that questions about sexual orientation could have been improved $\left[\chi^{2}(2,114)=8.3, p=0.016\right]$.

\section{Gender differences}

There were no significant differences between male and female participants in their referral, assessment or treatment experiences. Significantly more women than men were interested in a bisexual group $\left[\chi^{2}(2,108)=6.064, p=0.048\right]$, reflective of more women identifying as bisexual than men.

\section{Thematic analysis of qualitative feedback}

Results of the thematic analyses are summarised below, with main themes shown in Fig. 1.

\section{Experiences of psychological services}

The main themes identified in relation to experiences of psychological services were: prejudice or discrimination, reluctance to disclose, discussion of LGBQ+ identity in treatment and inadequate clinician awareness and understanding.

\subsection{Prejudice or discrimination}

\subsubsection{Fears of prejudice or discrimination}

Anticipation and anxiety around experiencing prejudice or discrimination during the process of accessing psychological services was an important theme. One participant noted: '[y]ou never know how a GP/health professional will react to you disclosing your sexuality'. LGBQ+ participants reported hypervigilance around disclosing their sexuality, based on past experiences of anti-LGBQ+ stigma:

'When you learn through experience that most people dislike you by default, every stranger, even those in positions of care, become threats.'

For the majority of participants, 'that [anxiety or apprehension] was unfounded'. One participant stated they avoid disclosure 'to ensure I minimize any bias, though [I] have not felt any to date'. There is a sense of self-protection amongst LGBQ+ participants even without experience or indication of a practitioner's prejudice. 
Table 4. Participant views about need for information/support regarding LGBQ+ specific issues $(n=136)$

\begin{tabular}{|c|c|c|c|c|c|c|c|c|c|c|c|c|}
\hline \multicolumn{13}{|c|}{ Views about information/support for LGBQ+ specific issues being available through the NHS } \\
\hline & \multicolumn{2}{|c|}{$\begin{array}{l}\text { Yes, and I } \\
\text { would be } \\
\text { willing to } \\
\text { access this } \\
\text { via the NHS }\end{array}$} & \multicolumn{2}{|c|}{$\begin{array}{l}\text { Yes, but not } \\
\text { from an } \\
\text { NHS service }\end{array}$} & \multicolumn{2}{|c|}{$\begin{array}{l}\text { No, but it } \\
\text { should be } \\
\text { available } \\
\text { for others }\end{array}$} & \multicolumn{2}{|c|}{$\begin{array}{l}\text { No, and I } \\
\text { do not } \\
\text { think this } \\
\text { should } \\
\text { be } \\
\text { provided } \\
\text { by the } \\
\text { NHS }\end{array}$} & \multicolumn{2}{|c|}{ Not sure } & \multicolumn{2}{|c|}{ N/A } \\
\hline & $n$ & $\%$ & n & $\%$ & n & $\%$ & $n$ & $\%$ & $n$ & $\%$ & $n$ & $\%$ \\
\hline How being $L G B Q+$ might affect your mental health & 111 & 81.6 & 8 & 5.9 & 10 & 7.4 & 1 & 0.7 & 6 & 4.4 & - & - \\
\hline Feeling lonely or isolated as an LGBQ+ person & 95 & 69.9 & 25 & 18.4 & 9 & 6.6 & 0 & 0.0 & 4 & 2.9 & 3 & 2.2 \\
\hline Difficulties relating to your sex life & 95 & 69.9 & 21 & 15.4 & 15 & 11.0 & 1 & 0.7 & 4 & 2.9 & - & - \\
\hline Drug and alcohol use that is affected by being LGBQ+ & 89 & 65.4 & 12 & 8.8 & 27 & 19.9 & 3 & 2.2 & 5 & 3.7 & - & - \\
\hline Body confidence issues connected to my LGBQ+ identity & 88 & 64.7 & 23 & 16.9 & 17 & 12.5 & 2 & 1.5 & 6 & 4.4 & - & - \\
\hline Issues relating to gender identity or gender expression & 87 & 64.0 & 16 & 11.8 & 23 & 16.9 & 1 & 0.7 & 8 & 5.9 & - & - \\
\hline Developing your confidence as an LGBQ+ individual & 83 & 61.0 & 31 & 22.8 & 13 & 9.6 & 4 & 2.9 & 5 & 3.7 & - & - \\
\hline Accepting your sexual orientation & 81 & 59.6 & 37 & 27.2 & 13 & 9.6 & 2 & 1.5 & 1 & 0.7 & 2 & 1.5 \\
\hline How to access support from other LGBQ+ people & 81 & 59.6 & 39 & 28.7 & 8 & 5.9 & 1 & 0.7 & 7 & 5.1 & - & - \\
\hline Confusion or uncertainty about your sexual orientation & 80 & 58.8 & 38 & 27.9 & 13 & 9.6 & 1 & 0.7 & 4 & 2.9 & - & - \\
\hline Dealing with other people's reactions to your sexual orientation & 78 & 57.4 & 37 & 27.2 & 14 & 10.3 & 1 & 0.7 & 6 & 4.4 & - & - \\
\hline How to cope with LGBQ+ prejudice or discrimination & 77 & 56.6 & 44 & 32.4 & 11 & 8.1 & 0 & 0.0 & 4 & 2.9 & - & - \\
\hline Relationships with partner(s) as an LGBQ+ person & 72 & 52.9 & 44 & 32.4 & 14 & 10.3 & 1 & 0.7 & 5 & 3.7 & - & - \\
\hline Coming out about your sexual orientation & 69 & 50.7 & 45 & 33.1 & 15 & 11.0 & 1 & 0.7 & 6 & 4.4 & - & - \\
\hline Knowing which sexual orientation label or identity feels best for you (if any) & 65 & 47.8 & 38 & 27.9 & 19 & 14.0 & 6 & 4.4 & 8 & 5.9 & - & - \\
\hline How to fight $L G B Q+$ prejudice or discrimination & 57 & 41.9 & 59 & 43.4 & 13 & 9.6 & 2 & 1.5 & 5 & 3.7 & - & - \\
\hline
\end{tabular}

N/A, not applicable. 


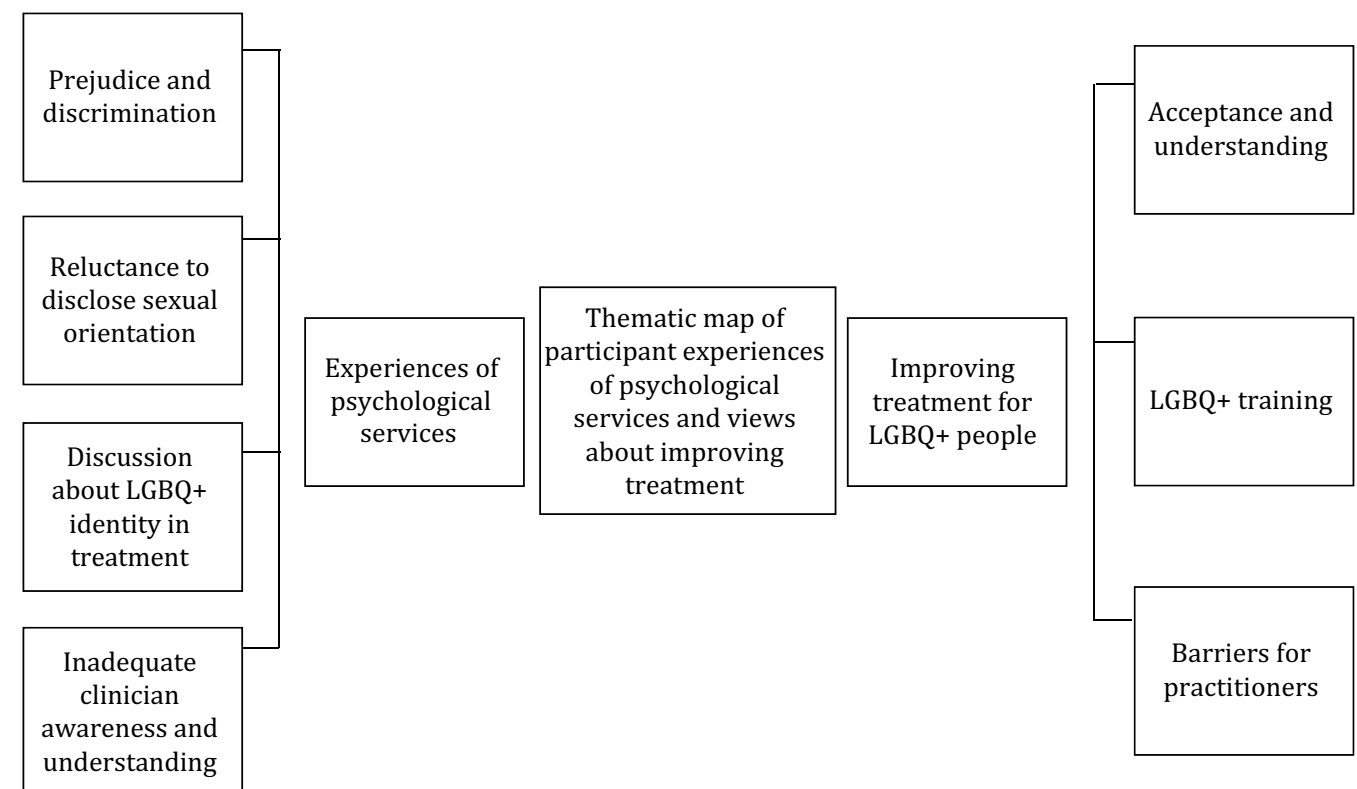

Figure 1. Main themes of thematic analysis.

\subsubsection{Biphobia}

Biphobia was by far the most discussed form of prejudice during the process of accessing treatment. It manifested as stereotyping, e.g. bisexuality is 'immature' or 'lots of young people "think" they are bisexual', and scrutinization, i.e. 'a load of questions about whether I was "always this way" and do I think it's a "permanent" thing'. One participant stated: 'I saw her notepad which said "bisexual?" - for me, there is no question there, it's who I am'.

Bisexual+ people were also mislabelled as 'lesbian despite me not telling her that at all', or spending 'the better part of a session ... lecturing me about [my sexuality]', showing practitioners can approach the topic of bisexuality with a fixed idea of what bisexuality is, and an unwillingness to listen to the participants. Indeed, many participants reported practitioners 'did not understand my experiences as a bisexual person'. This meant bisexual participants 'edited' themselves when 'for instance, talking about former partners'. One participant summarizes: 'After listening to their biphobia, I sure as hell was not going to talk about anything truly important to me'.

\subsubsection{Homophobia}

Gay and lesbian participants reported that some professionals viewed their sexual orientation as something they 'needed help to get over'. Religious biases were experienced, with one participant reporting: 'A Christian GP told me that I was confused and I should pray to find support to be gay' and another participant encountering someone who 'was clearly completely freaked out by me being gay and atheist'. Further to this, participants felt their homosexuality was pathologized and treated as symptomatic of a mental disorder. In the words of one participant: 'I felt that I was often seen as histrionic just because I identified as gay - that certain information and behaviours were suddenly seen in a pathological light'. 


\subsubsection{Transphobia}

Transphobia was also often mentioned. As one participant phrased it, 'I feel my gender identity is very tied to my sexual orientation'. Misgendering the participant or their partners occurred. This was present even if participants were explicit about their gender identities, or that of their partners: 'I'd made it clear in the first five minutes of starting the first session that I'm a bisexual trans woman early in transition'. Some found that their gender identity distracted from the treatment, for example 'my therapist would ask why I was using the pronouns I was rather than focusing on the therapy'. There were further incidences of discomfort and 'weird look[s]' from practitioners around transgenderism and an unwillingness to learn, one participant even saying they were 'treated in a hostile way when [I] raised issues around homophobia and transphobia against a partner'.

\subsubsection{Being both BAME and $L G B Q+$}

Participants reported that health professionals showed little awareness of the potential impact of being both Black and minority ethnic (BAME) and LGBQ+ and neglected to ask about such experiences. As one participant said, 'I attempted to discuss aspects of intersectionality (both racial and sexuality) but quickly realized this was lost on my therapist so [I] was reluctant to address it again'. They felt these issues were 'downplayed, or ignored'. Participants reported witnessing direct discrimination, too: 'I saw Black bi friends receiving racism from NHS staff. One participant explained: ' $[\mathrm{M}] \mathrm{y}$ friend once attended a group therapy for gay men of 11 people - he was the only black person there and this had an impact on how comfortabl[y] he could speak about his experiences, i.e. racism in the gay community'.

\subsection{Reluctance to disclose}

1.2.1. Irrelevancy

Some participants said their orientation was not 'necessary' or 'relevant' to their treatment. They also 'didn't think it was any of [the practitioner's] business', and some participants did not identify as LGBQ+ at the time of seeking treatment.

\subsection{2. 'Never asked'}

A prominent theme was that questions about sexual orientation were 'never asked [...] So I didn't say anything'. Some participants 'had to self-declare my sexual orientation, as it was relevant to my experiences with depression'. Some practitioners also assumed participants were heterosexual. This was particularly pertinent to bisexual participants. One bisexual participant describes: 'they seemed to be working under the assumption that I was heterosexual, due to knowledge of a previous boyfriend'. This meant 'there were issues ... that weren't explored because of the assumption that I was straight'. Participants noted that 'the questions [about relationships or sexuality] could be reworded so that isn't the case'.

\subsubsection{Self-protection}

A strong theme was avoiding disclosure to protect themselves due to 'the fear of it influencing the attitude I would receive'. There was a fear of disclosure 'interfer[ing] with therapy which is so hard to access anyway'. This links with hypervigilance, as participants highlighted: 'I learned to be extremely cautious from an early age'.

Participants felt they would 'have to justify my sexuality and gender identity', especially if their sexuality/gender was 'too out-there' and less well-known, e.g. pansexual, queer or non-binary. It was 'easier to just present myself as straight to avoid problems'; some participants felt 'lucky' that they were 'straight-passing'. 
In group therapy, participants struggled to be open with their sexuality as 'you have to out yourself to more people', so participants felt 'concerned about the reactions of other members of the group' to their sexuality. It was reported that it was the group more than the therapists' that prevented them from opening up around LGBQ+ issues, but others found therapists 'sided with vocally homophobic members of the group against me'.

\subsection{Discussion about $L G B T Q+$ identity in treatment}

\subsubsection{Over-attribution of difficulties to sexual orientation}

Many participants wished to make clear that their experiences as a sexual minority were 'not the only cause of my issues'. They were concerned about and 'defensive' towards their therapist assuming or implying that their sexual orientation was the sole cause of their mental difficulties or 'consider[ed] ... a mental disorder in and of itself. In the words of one participant: 'Because [I]'m gay and trans people tend to assume everything mentally wrong with me is related to that'.

Some participants were referred away from NHS psychological treatment to LGBTQ+ services or discharged, despite 'want [ing] further treatment'. One participant elaborates: '[When I went] to see my local community mental health team ... [and] mentioned that [I] was queer they decided that it was unnecessary for me to carry on with them and to just talk to my [GP], whereas [I] knew that while it had an impact it wasn't the only reason [for my psychological difficulties]'.

\subsubsection{Neglecting sexual orientation}

Participants also found that their sexual orientation was not 'discussed very deeply' and that it 'was often ignored or downplayed'. Thus they were not 'able to explore whether my sexuality was contributing to the way I felt about myself. Even when the impact of homophobia in a participant's mental health was 'mention[ed] a number of times', they were not referred to '[LGBTQ+] support groups or counselling nor provided with [LGBTQ+] specific resources'. One participant highlighted: 'Some of the past issues I was dealing with were due to homophobic bullying, I'm not sure I was aware that this was the case at the time, but because of the lack of questions about it, it was not something touched upon'.

Practitioners had not 'appreciated how important [sexuality] was to me' and there was a 'sense of not wanting to talk about it'. Resultantly, participants 'felt like it would be pathologized' if they 'shoe-horn[ed] it into the conversation'. Participants suggested practitioners should start '[a]sking about it so I didn't have to bring it up' and that a middle ground could be reached where sexuality 'wouldn't ... be focused on, it might be good for [practitioners] to be aware of it'.

\subsection{Inadequate clinician awareness and understanding}

\subsubsection{LGBTQ+ identities}

Participants expressed a need for ' $[\mathrm{m}]$ ore options, understanding and knowledge' around LGBTQ+ identities from practitioners. Others expressed that '[i]f counsellors were actually aware of the difference between gender identity and sexuality, that'd be a nice start'. One participant thought that with 'a good enough understanding' practitioners 'would have picked up on' the use of gender-neutral pronouns and 'changed their language'.

Bisexual+ participants especially felt practitioners did not 'fully understand how you could be attracted to more than one gender' or 'have anything in the area of bisexuality' to offer them. They experienced 'a lack of understanding, or awkwardness' around their orientation; for example, one participant found that 'many people [don't] understand what being pansexual means'.

Within this, practitioners struggled with 'identity, behaviour [and] attraction [being] different in one individual', as one participant discusses in their example: 'I am bisexual, and very attracted 
to people of all genders ... and I would not feel safe in an intimate relationship with just about any cis man, nor most cis women'.

One participant suggests that if the staff [were] more well informed about ... sexual orientations, patients would have an easier time answering questions and feel less pressured to explain their sexuality'.

\subsubsection{LGBTQ+ issues and experiences}

Participants 'avoided talking about [sexual minority] issues in depth as I felt [practitioners] didn't understand' or may not be aware of 'a difference in issues for someone who was gay'. Coming out was strongly identified as an area that practitioners did not understand, particularly around coming out 'late' in life and the 'enormity' of coming out, especially 'to my partner and family'. Generally, they lacked understanding around 'the difficulties ... with my family and my sexuality'.

Participants felt the 'distress of prejudice from members of the public' was not understood or discussed, even if it 'might have been relevant and helpful': 'I felt that they did not understand that my fears about being in public as a visibly gay/gender-nonconforming woman are based in fears over my ${ }^{\star}$ safety $^{\star}$ rather than some kind of irrational social anxiety'.

Practitioners did not grasp '[w]hat it's actually like to grow up scared of being gay'. A participant highlighted, '[g]rowing up concealing an identity, bullying and abuse' all impacted self-perception and 'interactions with others'; yet, for one participant, 'even when talking about bullying ... it was never touched upon as a potential cause of some of my issues'.

Participants also felt 'another LGBT person would understand more' as a therapist as '[i]f you're not [LGBTQ+] you don't know what it's like'. However, 'heterosexual therapists who are adequately trained would also be able to [make participants feel comfortable]'.

Overall, participants expressed a need for '[m] ore awareness of the specifics of mental health issues as they relate to homosexuality, i.e. higher levels of body dysmorphia in gay men'.

\section{Improving treatment}

For questions about how treatment could be improved, the following themes were identified: acceptance and understanding, LGBTQ+ training, improving confidence in therapists and services, and improving services for all.

\subsection{Acceptance and understanding}

Participants' positive experiences in accessing psychological help prominently centred on practitioners who demonstrated understanding. This made participants 'feel more comfortable in the sessions', as did practitioners being 'non-judgemental' and 'open and accepting', and handling issues 'professionally and objectively'. This made it seem 'completely normal to present as LGBT' for participants.

Another important theme is having 'openly gay' practitioners, which 'positively affected the trust in our doctor:patient relationship' and '[is] just so helpful because he has an understanding of the issues that I am facing'. Disclosing 'personal experience' with LGBQ+ culture also 'strengthened our relationship leading to a more successful CBT session'.

\section{2. $L G B T Q+$ training}

\subsubsection{How to address sexual orientation}

Good practice was viewed as involving 'asking questions about sexual orientation instead of making assumptions' and not 'assum[ing] ... sexual orientation is the major playing part in the [psychological] problem'; instead, 'let the person tell you where it fits in'. As one 
participant explains: 'They should be trained in specific issues the community faces ... Equally they shouldn't assume everyone experiences this'.

Participants also suggested using 'non gendered language' and 'inclusivity in equality monitoring forms' to normalize presenting as LGBTQ+.

\subsubsection{Education}

An important theme was LGBTQ+ training for practitioners so 'it doesn't feel like you have to explain yourself on top of explaining what's going on in your head' as 'having to explain over and over again makes you feel less accepted in society'.

This included education on 'different sexualities and how they can impact a person', 'beyond gay/straight/trans*'; how gender 'relates (or doesn't) to sexuality'; and how being LGBTQ+ 'affects day to day life' through 'micro-aggressions . ... as well as more macro discrimination', e.g. bullying. 'Bi-erasure' was particularly implicated here, as one participant explains: ' $\mathrm{Bi}+$ people, especially women, trans people and trans bi women experience some of the highest rate[s] of social exclusion, partner violence, poverty and other traumas of any population'.

Coming out was perhaps the most referenced area practitioners needed educating in, regarding the 'pressure from society/family [and] from self to come out, and 'variation in coming out', e.g. 'coming out almost daily to new people'. Within this, 'unpacking internalized shame' or 'help with knowing it's okay to be confused' should be addressed, too, with the aim of the practitioner helping participants 'with coming out to family and friends', but also in 'coming to a place with being okay in the world, and [with] our place in it, because so many of us have never felt like we belong'.

Participants felt that this training should be 'led by a therapist who specializes in LGB-issues' or by 'local [LGBTQ+] charities', but specifically that the NHS should be '[p]aying LGBQ+ people, particularly people from bi+ led services, to train staff.

Further training on intersectionality regarding LGBTQ+ people of colour to 'address [the] concerns of not just cis white gay men' carried similar sentiments of being 'led by professional BAME anti-racism trainers'.

\subsection{Barriers for practitioners}

\subsubsection{Pervasive stigma}

Participants felt that pervasive stigmatizing attitudes or stereotypes attached to LGBQ+ identities may make it harder for therapists to treat certain groups. This concern was particularly apparent when participants were asked about whether lesbian and bisexual women should have an exclusive group to process childhood trauma. Although most participants supported the NHS offering a specific intervention for this group, participants highlighted the 'erroneous theory that people are lesbian or bisexual `because ${ }^{\star}$ of childhood abuse or trauma' may 'promote negative stereotypes among healthcare professionals'. As one participant explains: '... if you start treating queer women specifically like they must have been abused and not straight women ... it implies a causal link between abuse and lesbianism'.

Instead, some participants felt it is sufficient to be aware of the issue and to prove support irrespective of sexuality' to negate this issue, making '[c]hildhood abuse services ... equally accessible to all'.

\subsubsection{Improving confidence in therapists and services}

This theme describes the tendency of participants to mistrust practitioners and their ability to deliver helpful, informed services to LGBQ+ people. Participants' did not open up to therapists because they 'didn't trust them', whilst others said to 'expect low confidence' from sexual minorities towards any LGBQ+ NHS services. They felt the NHS should invest 
resources into building confidence in the service' as LGBQ+ people have low standards set currently; as one participant said, 'just seeing someone who isn't a homophobe would be a step up'.

Participants across all genders also had 'the most positive experience' with female as opposed to male therapists. They felt a woman would 'validate my gender' and be 'easier to talk to ... about intimate issues'. Participants attributed apprehension about seeing a 'straight male therapist' to 'being a gay man'. Thus therapists who were male, cis, heterosexual and/or older appeared more difficult to establish a good therapeutic relationship with because participants 'felt no connection' with them, did not think they 'would be taken seriously' or 'had to manage my tone specifically when talking about straight people'. One participant stated: 'The fact my therapist was a much older man may have biased how much I felt he could understand my experience in a meaningful way'.

\subsubsection{Improving services for all}

There was a theme that services 'could have been improved for everyone', irrespective of their sexual orientation. Therapies were seen as 'extremely standardized' and 'impersonal', with participants at 'the mercy of what therapists are available'. 'Waiting list[s]' and long waiting times left participants feeling 'forgotten and pushed to the side'. Many participants did not request the gender/orientation of their therapist(s) because they were 'still struggling to believe' they 'deserved NHS treatment with it being so underfunded' in the first place, or 'didn't feel able to be selective' because 'therapy is so hard to access' already.

\section{Discussion}

\section{Summary of key findings}

Although $42 \%$ had been concerned about stigma or discrimination beforehand, only $15 \%$ reported that they had experienced it during the process itself. It is positive that discriminatory experiences were lower than they had expected. However, under the 2010 Equality Act, LGBQ+ people should not experience any sexuality-based inequalities in health service provision. In this study, $14 \%$ of participants felt their treatment was negatively impacted by their sexuality, and $22 \%$ felt that their therapist did not have a good understanding of their experiences as LGBQ+ people. Consequently, it is clear that some LGBQ+ people still face specific barriers in IAPT and primary care psychological services. Participants reported: prejudice and discrimination, particularly biphobia; poor awareness and understanding of sexual minority identities and community-specific challenges; an over- or under-emphasis on the role of sexuality in their psychological difficulties (including pathologizing their sexuality); and a lack of disclosure due to self-protection and heteronormativity. There were not many differences between cisgender men and women or monosexual and bisexual+ participants other than lower disclosure rates in the latter.

\section{Prejudice and discrimination}

Findings that $15 \%$ of participants experienced stigma or discrimination whilst accessing NHS psychological care suggests there may be a lack of monitoring for discrimination within these services in accordance with the 2010 Equality Act and inadequate LGBTQ+ training amongst practitioners, against NHS recommendations (NHS, 2015). This may also be under-estimated as $33.6 \%$ of participants were not out to their practitioners. Whilst it cannot be identified as the sole contributor, due to wider cultural stigma and other variables that produce higher LGBQ+ mental illness rates (e.g. childhood victimization), it is possible that these experiences may contribute to the reported poorer treatment outcomes of LGBQ+ people. 


\section{Sexual orientation disclosure}

The reports of heteronormative assumptions and stereotyping by some therapists suggest that participants' hypervigilance for stigma processes was sometimes justified. Stereotyping and heteronormative assumptions had a clear impact on some participants' ability to disclose and explore their sexuality. The frequency and severity of bisexual stereotyping was a prominent feature of the qualitative analysis and bisexual participants disclosed their sexuality significantly less than lesbians and gay men. For bisexual participants, heteronormativity operated with bi-negative stereotyping of bisexuals as confused, untrustworthy, promiscuous, or having to 'prove' their sexuality (Armstrong and Reissing, 2014; Zivony and Lobel, 2014).

Some participants did present more benign reasons for non-disclosure, such as not being aware they were LGBQ+ at the time, or feeling it was irrelevant to their therapy. Sexuality may have also been less salient for some sexual minority patients who did not take part in the study. However, within our sample, being assumed to be heterosexual and concerns about negative attitudes or discrimination were the most prominent reasons for non-disclosure. Participants who do not disclose their sexual minority identity are prevented from exploring the potential impact of their sexuality-related experiences on their psychological problems. This may have adversely affected the success of their treatment.

Participants' reluctance to disclose their sexuality may be particularly detrimental to the treatment outcomes of certain sexual minority people. This includes closeted LGBQ+ people, people who are openly LGBQ+ but still coming to terms with aspects of their sexual minority identity, and LGBQ+ people whose identities are not widely recognized in society (e.g. pansexual people) who would have to further explain their identities. These groups may lose out the most from being deprived of a therapeutic relationship that acknowledges and legitimizes their sexuality, and the feelings and experiences connected to it. This is perhaps true even for some participants who deemed their sexuality irrelevant, because they may not have been aware of the ways their sexual minority experiences impacted them without the ability to explore this in a therapeutic setting.

\section{Inconsistent emphasis on sexual orientation by practitioners}

Practitioners appeared to often struggle in knowing how best to acknowledge the role that difficult experiences LGBQ+ people face plays in mental health and allowing participants to explain the role of their sexuality in their own mental health. Some implied that being a sexual minority was a mental health problem in itself, while others neglected to address the psychological impact of minority stress processes at all. Hatzenbuehler (2009) proposes that it is the interaction of both minority-specific stressors and general psychological maintenance processes (e.g. rumination and avoidance) that contribute to psychological difficulties in minority groups. This nuance appeared overlooked.

\section{Impact on therapy}

Participants often felt misunderstood by their therapist and disillusioned in the therapy process, e.g. $27.2 \%$ felt they could not discuss certain topics with their therapist and $52.2 \%$ felt that psychological care could be improved. In a systematic review, Lambert and Barley (2001) established that a good therapeutic relationship was associated with positive treatment outcomes, hinging on client-practitioner relatability and individualization of treatment. As such, the deficiency participants felt in this area could plausibly contribute to poorer treatment outcomes previously identified for bisexual and sexual minority clients in IAPT services (Rimes et al., 2019). This is supported by the fact that an overwhelming majority $(87.5 \%)$ of participants still agreed more LGBTQ+ training is necessary and showed support 
for LGBQ+ specific treatments to be available on the NHS, and many expressed that their therapeutic relationship could be improved with increased awareness and understanding.

\section{Limitations}

Due to the lack of appropriate existing scales, the questionnaire was developed for the purpose of this study and had not undergone psychometric assessment. In addition, self-report questionnaires are all subject to biases such as memory bias. Social desirability effects should have been reduced by the anonymous nature of the questionnaire. Many factors between completing treatment and answering the questionnaire may have informed participants' perspective on what happened, such as whether the treatment was perceived to have lasting beneficial effects or the views of others if treatment experiences were discussed. Self-report data also mean that questions such as 'Was your treatment service an IAPT?' may have produced unreliable results, as participants may not know nor remember. Furthermore, whether participants in this study showed reliable recovery post-treatment was not measured, so no direct links can be made between negative treatment experiences and therapy outcomes.

Many participants in this study did not disclose their sexual orientation to the practitioner(s). This means that the amount of potential stigma and discrimination in psychological services may have been obscured, because if practitioners were not aware of participants' sexuality, their prejudices might not have become apparent. The lower disclosure in bisexual participants requires replication as the group comparisons were not corrected for multiple testing due to their exploratory nature. However, this finding is consistent with previous literature (e.g. Balsam and Mohr, 2007; Durso and Meyer, 2013).

Arguably the most significant limitation of this study is the demographic make-up. Whilst we gathered a relatively even number of monosexual to multi-gender attracted individuals, across a wide age range, almost $40 \%$ of the sample had a university degree, and almost all participants were White. This means participants' experiences as reported in this study may not be generalizable to other members of the LGBQ+ community who are less socially privileged. Certain sexual minorities were also under-represented in our responses, e.g. there were only seven (cisgender) bisexual men and two asexual participants and this also prevented further statistical comparisons involving such subgroups. There are limitations in combining LGBTQ+ experiences together for some of the analyses, as different subgroups may experience different types of stigma or treatment barriers.

\section{Implications}

Future research

Future research should investigate whether the negative treatment experiences in relation to sexual orientation issues are associated with poorer treatment outcomes. The thematic analysis raised issues of cultural competence from practitioners, the middle-class focus of services, and racism within the LGBQ+ community, as well as classism.

Future research should compare treatment experiences between subgroups within the LGBQ+ community, including differences between gay men and lesbian women, and between bisexual men and bisexual women. Further research should be conducted with a bisexual+ focus considering the prevalence of biphobia in this sample and evidence of poorer treatment outcomes for bisexual men and women in IAPT services (Rimes et al., 2019). More research is also needed which targets groups with other characteristics that were under-represented in the present study (e.g. BAME people). Future research could explore transgender, non-binary and gender-diverse experiences, of any sexuality, in psychological services, and focus on the intersection of transphobia and sexual minority stigma. Due to poor data monitoring of 
gender identity, little is known about whether gender minority individuals have poorer treatment outcomes; this needs urgent attention.

\section{Treatment implications}

There is a pervasive stigma still present in NHS services towards LGBQ+ people, ranging from explicit religious biases or dismissal of sexual attraction, to stereotyping, to heteronormative approaches to client interactions. This leads participants to distrust practitioners, not disclose their sexuality, expect very little from the services and anticipate discrimination (reinforcing hypervigilance). Training needs for practitioners are outlined below. Based on participant answers, training should cover LGBTQ+ identities and how adverse LGBTQ+ experiences may impact mental health.

\section{LGBTQ+ training}

\section{Improved understanding of sexual minority identities}

Training would deconstruct sex versus gender, romantic versus sexual attraction and what different sexual identities mean. The aim would be to standardize screening for sexuality across the board by discouraging practitioners from making assumptions about clients, e.g. 'they are heterosexual as they have had children', and instead ask questions. Herein, stereotypes about sexualities should be addressed and debunked, e.g. linking bisexuality to promiscuity. It should also discuss how other identities intersect with sexuality, such as ethnicity, religion or class. An environment that encourages people to discuss their biases without judgement would be needed to cultivate a successful training session that dismantles implicit biases as well as explicit ones.

\section{Improved understanding of experiences of sexual minority individuals}

Practitioners should be aware of LGBTQ+ specific challenges, including coming out as a sexual minority, concealing LGBQ+ identities, bullying based on sexuality or gender non-conformity, increased rates of childhood victimization, and internalized stigma. Therapist understanding should include how sexual orientation experiences can intersect with other identities, e.g. religion and culture; and further how these interplay with wider anti-LGBTQ+ stigma. The aim would be to educate staff on potential contributors to clients' psychological difficulties and in tackling anxieties around these issues without (a) increasing or invalidating clients' apprehension/hypervigilance, and (b) ignoring the social stigma that will continue to inform clients' views of themselves and others. Practitioner training should also address orientationspecific challenges, such as double discrimination in bisexuals, or misgendering in sexual minority individuals who are also transgender or non-binary.

\section{Creating a safe space}

Even with improved therapist training, clients may still not feel safe in a clinical setting discussing sexuality-related issues, due to fears of prejudice or discrimination. Thus practitioners should become educated on how to explicitly create an accepting environment. Based on participants' suggestions, this would include: (a) inclusive language, e.g. practising gender-neutral pronouns when asking about partners, saying 'all genders' instead of 'both genders'; (b) inclusive images and examples, such as LGBTQ+ posters in waiting rooms and using same-gender relationships as vignettes; and (c) in groups, establishing ground rules that deliberately denounce discriminatory language and attitudes, to give space for clients to disclose their sexuality comfortably. 


\section{Specific therapies for $L G B Q+$ individuals}

Developing LGBQ+ specific therapies would be one way of trying to ensure a safe environment and more effective treatment for LGBQ+ clients. Opportunities in therapy to discuss LGBQ+ issues would convey explicit acceptance of LGBQ+ identity and allow exploration of the impact of minority stress experiences on the client's mental health. This could be an LGBQ+ specific group or within individual therapy. It would be important to pilot this, then test as part of a randomized controlled trial. Pachankis and colleagues (Pachankis et al., 2015) have found promising results from a specific CBT intervention for sexual minority young men.

\section{Bisexual + focus}

Bisexual+ individuals did not display many differences overall compared with lesbian and gay individuals, but were significantly less likely to disclose their sexuality and more likely to feel there were topics they could not discuss with their therapist. In the qualitative, biphobia was prevalent in terms of stereotyping, heteronormativity and a lack of understanding of both their sexuality and biphobic stigma.

Training needs to focus on the nuances of bisexuality, such as how attraction differs between genders, being divided unwillingly between two communities (the LGBQ+ community and heterosexual community), double discrimination (from these two communities towards bisexual people), and stereotyping. This is especially important as bisexuals encounter elevated levels of mental illness compared with lesbians and gay men and are therefore particularly vulnerable. Moving forward, the NHS should make a commitment to deliver training with a bi+ focus. In assessment and therapy, this could be displayed as routinely asking sexual orientation, whether or not a client discloses relationship history with one gender, instead of assuming monosexuality; and, on disclosure of bisexuality, exploring the impact of biphobia with a background awareness of what it could entail.

\section{Conclusions}

Many LGBQ+ people, particularly bisexual individuals, are not having their treatment needs met due to stigma-related obstacles within NHS IAPT and primary care psychological services. More needs to be done to ensure that LGBQ+ people are guaranteed (1) protection from prejudice and discrimination, and (2) understanding and inclusivity around LGBQ+ related issues. This would be in adherence to the 2010 Equality Act and current NHS recommendations. This study provides a basis for future research and clinical training to improve sexual minority treatment outcomes in NHS IAPT and primary care services.

Acknowledgements. We would like to thank all the participants who took part in this study.

Conflicts of interest. None.

Ethics statement. This study received ethical approval by King's College London Research Ethics Committee (HR-17/18-5303).

Financial support. None.

Key practice points

(1) Sexual minorities still encounter stigma-related barriers in NHS IAPT and primary care services, which may impact on their mental health care.

(2) Bisexual individuals reported additional stigma processes to lesbian and gay participants, such as biphobic stereotyping, heteronormativity and lower disclosure rates.

(3) Practitioners require training about LGBQ+ issues, including how to ask about and discuss LGBQ+ identities and the impact of LGBQ+ related experiences on their client's mental health.

(4) Sexual minority identity needs to be consistently recorded and inequalities in treatment outcomes audited and addressed where needed. 


\section{Further reading}

British Psychological Society (2019). Guidelines and Literature Review for Psychologists Working Therapeutically with Gender, Sexuality and Relationship Diversity. Retrieved from: https://www.bps.org.uk/sites/bps.org.uk/files/Policy/ Policy\%20-\%20Files/Guidelines\%20for\%20psychologists\%20working\%20with\%20gender\%2C\%20sexuality\%20and\% 20relationship\%20diversity.pdf

National Health Service (2015). Improving Lesbian Gay Bisexual and Trans (LGBT) equality across the NHS: a paper for the Equality and Diversity Council. Retrieved from: https://www.england.nhs.uk/wp-content/uploads/2015/11/edc1-lgbtequal-pap-20-10-15.pdf

Rimes, K. A., Broadbent, M., Holden, R., Rahman, Q., Hambrook, D., Hatch, S. \& Wingrove, J. (2018). Comparison of treatment outcomes between lesbian, gay, bisexual and heterosexual individuals receiving a primary care psychological intervention. Behavioural and Cognitive Psychotherapy, 46, 332-349. doi: 10.1017/S1352465817000583

\section{References}

Andersen, J. P., \& Blosnich, J. (2013). Disparities in adverse childhood experiences among sexual minority and heterosexual adults: results from a multi-state probability-based sample. PLOS One, 8. doi: 10.1371/journal.pone.0054691

Armstrong, H. L., \& Reissing, E. D. (2014). Attitudes toward casual sex, dating, and committed relationships with bisexual partners. Journal of Bisexuality, 14, 236-264. doi: 10.1080/15299716.2014.902784

Balsam, K. F., \& Mohr, J. J. (2007). Adaptation to sexual orientation stigma: a comparison of bisexual and lesbian/gay adults. Journal of Counselling Psychology, 54, 306-319. doi: 10.1037/0022-0167.54.3.306

Bostwick, W., \& Hequembourg, A. (2014). 'Just a little hint': bisexual-specific microaggressions and their connection to epistemic injustices. Culture, Health and Sexuality, 16, 488-503. doi: 10.1080/13691058.2014.889754

Braun, V., \& Clarke, V. (2006). Using thematic analysis in psychology. Qualitative Research in Psychology, 3, 77-101. doi: 10. 1191/1478088706qp063oa

Chakraborty, A., McManus, S., Brugha, T. S., Bebbington, P., \& King, M. (2011). Mental health of the non-heterosexual population of England. British Journal of Psychiatry, 198, 143-148. doi: 10.1192/bjp.bp.110.082271

Doan Van, E. E., Mereish, E. H., Woulfe, J. M., \& Katz-Wise, S. L. (2019). Perceived discrimination, coping mechanisms, and effects on health in bisexual and other non-monosexual adults. Archives of Sexual Behaviour, 48, 159-174. doi: 10.1007/ s10508-018-1254-z

Durso, L. E., \& Meyer, I. H. (2013). Patterns and predictors of disclosure of sexual orientation to healthcare providers among lesbians, gay men, and bisexuals. Sexual Research and Social Policy, 10, 35-42. doi: 10.1007/s13178-012-0105-2

Dyar, C., \& London, B. (2018). Longitudinal examination of a bisexual-specific minority stress process among bisexual cisgender women. Psychology of Women Quarterly, 42, 342-360. doi: 10.1177/0361684318768233

Elliott, M. N., Kanouse, D. E., Burkhart, Q., Abel, G. A., Lyratzopolous, G., Beckett, M. K., Schuster, M. A., \& Roland, M. (2015). Sexual minorities in England have poorer health and worse health care experiences: a national survey. Journal of General Internal Medicine, 30, 9-16. doi: 10.1007/s11606-014-2905-y

Feinstein, B. A., Dyar, C., \& London, B. (2016). Are outness and community involvement risk or protective factors for alcohol and drug abuse among sexual minority women? Archives of Sexual Behavior, 46, 1411-1423. doi: 10.1007/ s10508-016-0790-7

Friedman, M. S., Marshal, M. P., Guadamuz, T. E., Wei, C., Wong, C. F., Saewyc, E. M., \& Stall, R. (2011). A meta-analysis of disparities in childhood sexual abuse, parental physical abuse, and peer victimization among sexual minority and sexual non-minority individuals. American Journal of Public Health, 101, 1481-1494. doi: 10.2105/AJPH.2009.190009.

Hatzenbuehler, M. L. (2009). How does sexual minority stigma 'get under the skin'? A psychological mediation framework. Psychological Bulletin, 135, 707-730. doi: 10.1037/a0016441

Hatzenbuehler, M. L., \& Pachankis, J. E. (2016). Stigma and minority stress as social determinants of health among lesbian, gay, bisexual, and transgender youth: research evidence and clinical implications. Pediatric Clinics of North America, 63, 985-997. doi: 10.1016/j.pcl.2016.07.003

Lambert, M. J., \& Barley, D. E. (2001). Research summary on the therapeutic relationship and psychotherapy outcome. Psychotherapy: Theory, Research, Practice, Training, 38, 357-361. doi: 10.1037/0033-3204.38.4.357

Legate, N., Ryan, R. M., \& Weinstein, N. (2012). Is coming out always a 'good thing'? Exploring the relations of autonomy support, outness, and wellness for lesbian, gay, and bisexual individuals. Social Psychological and Personality Science, 3 , 145-152. doi: 10.1177/1948550611411929

Li, G., Kung, K. T. F., \& Hines, M. (2017). Childhood gender-typed behaviour and adolescent sexual orientation: a longitudinal population-based study. Developmental Psychology, 53, 764-777. doi: 10.1037/dev0000281

Meyer, I. H. (2003). Prejudice, social stress, and mental health in lesbian, gay, and bisexual populations: conceptual issues and research evidence. Psychological Bulletin, 129, 674-697. doi: 10.1037/0033-2909

Mittleman, J. (2019). Sexual minority bullying and mental health from early childhood through adolescence. Journal of Adolescent Health, 64, 172-178. doi: 10.1016/j.jadohealth.2018.08.020 
Mustanski, B., Andrews, R., \& Puckett, J. A. (2016). The effects of cumulative victimization on mental health among lesbian, gay, bisexual, and transgender adolescents and young adults. American Public Health Association, 106, 527-533. doi: 10. 2105/AJPH.2015.302976

NHS Equality and Diversity Council (2015). Improving Lesbian Gay Bisexual and Trans (LGBT) Equality Across the NHS: a Paper for the Equality and Diversity Council. Retrieved from: https://www.england.nhs.uk/wp-content/uploads/2015/11/ edc1-lgbt-equal-pap-20-10-15.pdf

NHS Digital (2017). Psychological Therapies: Annual Report on the Use of IAPT Services. Retrieved from: https://digital.nhs. uk/data-and-information/publications/statistical/psychological-therapies-annual-reports-on-the-use-of-iapt-services

Pachankis, J. E. (2007). The psychological implications of concealing a stigma: a cognitive-affective-behavioral model. Psychological Bulletin, 133, 328-345. doi: 10.1037/0033-2909.133.2.328

Pachankis, J. E., Hatzenbuehler, M. L., Rendina, H. J., Safren, S. A., \& Parsons, J. T. (2015). LGB-affirmative cognitivebehavioral therapy for young adult gay and bisexual men: a randomized controlled trial of a transdiagnostic minority stress approach. Journal of Consulting and Clinical Psychology, 83, 875-889. doi: 10.1037/ccp0000037

Plöderl, M., \& Tremblay, P. (2015). Mental health of sexual minorities. A systematic review. International Review of Psychiatry, 27, 367-385. doi: 10.3109/09540261.2015.1083949

Rimes, K.A., Broadbent, M., Holden, R., Rahman, Q., Hambrook, D., Hatch, S., \& Wingrove, J. (2018). Comparison of treatment outcomes between lesbian, gay, bisexual and heterosexual individuals receiving a primary care psychological intervention. Behavioural and Cognitive Psychotherapy, 46, 332-349. doi: 10.1017/S1352465817000583

Rimes, K. A., Ion, D., Wingrove, J., \& Carter, B. (2019). Sexual orientation differences in psychological treatment outcomes for depression and anxiety: national cohort study. Journal of Consulting and Clinical Psychology (in press).

Roberts, A. L., Rosario, M., Corliss, H. L., Koenen, K. C., \& Austin, S. B. (2012). Elevated risk of posttraumatic stress in sexual minority youths: mediation by childhood abuse and gender nonconformity. American Public Health Association, 102, 1587-1593. doi: 10.2105/AJPH.2011.300530

Roberts, A. L., Rosario, M., Slopen, N., Calzo, J. P., \& Austin, S. B. (2013). Childhood gender nonconformity, bullying victimization, and depressive symptoms across adolescence and early adulthood: an 11-year longitudinal study. Journal of the American Academy of Child and Adolescent Psychiatry, 52, 143-152. doi: 10.1016/j.jaac.2012.11.006

Russell, S. T., Ryan, C., Toomey, R. B., Diaz, R., \& Sanchez, J. (2011). Lesbian, gay, bisexual, and transgender adolescent school victimization: implications for young adult health and adjustment. Journal of School Health, 81, 223-230. doi: 10.1111/j.1746-1561.2011.00583.x

Semlyen, J., King, M., Varney, J., \& Hagger-Johnson, G. (2016). Sexual orientation and symptoms of common mental disorder or low wellbeing: combined meta-analysis of 12 UK population health surveys. BioMed Central Psychiatry, 16. doi: $10.1186 / \mathrm{s} 12888-016-0767-\mathrm{Z}$

Steensma, T. D., van der Ende, J., Verhulst, F. C., \& Cohen-Kettenis, P. T. (2012). Gender variance in childhood and sexual orientation in adulthood: a prospective study. Journal of Sexual Medicine, 10, 2723-2733. doi: 10.1111/j.1743-6109.2012. 02701.x

Xu, Y., \& Zheng, Y. (2015). Prevalence of childhood sexual abuse among lesbian, gay, and bisexual people: a meta-analysis. Journal of Child Sexual Abuse, 24, 315-331. doi: 10.1080/10538712.2015.1006746

Zivony, A., \& Lobel, T. (2014). The invisible stereotypes of bisexual men. Archives of Sexual Behaviour, 43, 1165-1176. doi: $10.1007 / \mathrm{s} 10508-014-0263-9$ 
Appendix 1. Participant responses on referral, assessment and treatment patterns

\begin{tabular}{|c|c|c|}
\hline Referrals $(n=136)$ & $n$ & $\%$ \\
\hline \multicolumn{3}{|l|}{ Services through which referred } \\
\hline GP & 89 & 65.4 \\
\hline Another health professional & 16 & 11.8 \\
\hline Self-referral & 31 & 22.8 \\
\hline Secondary care services, e.g. hospitals & 3 & 2.2 \\
\hline Family or teachers & 2 & 1.5 \\
\hline Student services & 1 & 0.7 \\
\hline \multicolumn{3}{|l|}{ Service to which referred } \\
\hline An NHS talking therapies service & 95 & 69.9 \\
\hline GP counsellor & 24 & 17.7 \\
\hline Mind and other mental health charities & 12 & 8.8 \\
\hline Another talking therapies service & 4 & 2.9 \\
\hline Not sure & 4 & 2.9 \\
\hline \multicolumn{3}{|l|}{ Assessment or treatment received } \\
\hline Nothing - I was not offered an assessment & 5 & 3.7 \\
\hline Offered an assessment but did not attend or take up the offer & 7 & 5.1 \\
\hline Assessed and referred on to another service & 23 & 16.9 \\
\hline Assessed and offered treatment but did not start & 10 & 7.4 \\
\hline Started treatment but stopped before it was due to end & 21 & 15.4 \\
\hline Completed treatment and had no further help at that time & 49 & 36.0 \\
\hline Completed treatment and then referred on for further help & 21 & 15.4 \\
\hline Treatment received $(n=91)$ & $n$ & $\%$ \\
\hline \multicolumn{3}{|l|}{ Treatment type } \\
\hline CBT & 63 & 69.2 \\
\hline Group session(s) & 16 & 17.6 \\
\hline Guided self-help with a book or booklet & 12 & 13.2 \\
\hline Online computer programmes & 4 & 1.1 \\
\hline Online therapy & 4 & 1.1 \\
\hline Counselling & 38 & 41.8 \\
\hline $\begin{array}{l}\text { Another face-to-face therapy (including hypnotherapy, CAT, psychosexual } \\
\text { therapy, CBT and DBT in combination, DBT, EMDR and psychodynamic therapy) }\end{array}$ & 11 & 12.1 \\
\hline \multicolumn{3}{|l|}{ Format of therapy } \\
\hline One-to-one & 78 & 85.7 \\
\hline Group therapy & 10 & 11.0 \\
\hline Not applicable & 3 & 3.3 \\
\hline \multirow[t]{2}{*}{ Number of sessions (missing data $=2$ ) } & Mean & $S D$ \\
\hline & 11.6 & 7.9 \\
\hline
\end{tabular}

CAT, cognitive analytic therapy; DBT, dialectical behavioural therapy; EMDR, eye movement desensitization and reprocessing.

Cite this article: Foy AAJ, Morris D, Fernandes V, and Rimes KA. LGBQ+ adults' experiences of Improving Access to Psychological Therapies and primary care counselling services: informing clinical practice and service delivery. The Cognitive Behaviour Therapist. https://doi.org/10.1017/S1754470X19000291 